\title{
SIGNIFICADOS E VIVÊNCIAS MEDIANTE A INDICAÇÃO CIRÚRGICA PARA PACIENTES CARDÍACOS ${ }^{1}$
}

\author{
Shana Hastenpflug Wottrich ${ }^{2}$ \\ Universidade Federal de Santa Catarina, Florianópolis-SC, Brasil \\ Alberto Manuel Quintana \\ Valéri Pereira Camargo \\ Carlos Oclides Pereira de Quadros \\ Alexandre Antonio Naujorks \\ Universidade Federal de Santa Maria, Santa Maria-RS, Brasil
}

\begin{abstract}
RESUMO. Este é um estudo qualitativo, de cunho exploratório e descritivo, cujo objetivo consistiu em compreender os significados atribuídos à cirurgia cardíaca por pacientes pré-cirúrgicos. Para sua realização participaram quinze usuários de ambulatório de cardiologia de um hospital universitário. A coleta de dados aconteceu através de entrevistas semiestruturadas. A análise dos dados foi realizada através da análise de conteúdo, da qual emergiram quatro categorias: $A$ ansiedade da espera; A cirurgia e o medo; Expectativas de futuro após a cirurgia; e Religiosidade e introspecção. Os resultados mostram as repercussões emocionais decorrentes do caráter de imprevisibilidade atribuído à cirurgia, evidenciando um cenário de vulnerabilidade e de fragilização emocional. Constata-se a necessidade de refletir sobre aspectos da cirurgia que estão além do adoecimento físico, abarcando as mais diversas áreas profissionais e de conhecimento no âmbito da atenção à saúde.
\end{abstract}

Palavras-chave: Psicologia da Saúde; distúrbios do coração; cirurgia.

\section{MEANINGS AND EXPERIENCES FOLLOWING THE SURGICAL INDICATION FOR CARDIAC PATIENTS}

\begin{abstract}
This is a qualitative study, characterized as exploratory and descriptive. Its aim consisted on understanding the meanings attributed to the cardiac surgery by presurgical patients. Fifteen users of a cardiology outpatient clinic of a university hospital participated on the study. Data collection was carried out through semi-structured interviews. Data analysis was carried out through content analysis, emerging four categories: Anxiety of waiting; Surgery and fear; Expectations about the future after the surgery; and Religiosity and introspection. Results emphasize the emotional repercussions due to the unpredictable character attributed to surgery, evidencing a context of vulnerability and emotional fragility. Such results highlight the need for reflection concerning aspects of the surgery that are beyond the physical body, covering the several fields of knowledge and professionals who are involved on health care.
\end{abstract}

Key words: Health psychology; heart disorders; surgery.

\section{SIGNIFICACIÓN Y VIVENCIAS POR MEDIO DE LA INDICACIÓN QUIRÚRGICA PARA PACIENTES CARDÍACOS}

RESUMEN. Este es un estudio cualitativo, de carácter exploratorio y descriptivo, cuyo objetivo consistió en comprender los significados atribuidos a la cirugía cardíaca por pacientes prequirúrgicos. Participaron 15 usuarios de ambulatorio de cardiología de un hospital universitario. La colecta de datos ocurrió a través de entrevistas semi-estructuradas. El análisis de datos fue realizado a través de análisis de contenido, emergiendo cuatro categorías: La ansiedad de espera; La cirugía y el miedo; Expectativas de futuro después de la cirugía; y Religiosidad e introspección. Los resultados enfatizan las repercusiones emocionales mediante al carácter de imprevisión atribuido a la cirugía, evidenciando un escenario de vulnerabilidad y de fragilidad emocional. Se constata la necesidad de reflexión sobre aspectos de la cirugía que están más

\footnotetext{
Apoio e financiamento: Coordenação de Aperfeiçoamento de Pessoal de Nível Superior (CAPES)..

2 Endereço para correspondência: Rua Dr. Bozano, 1051, ap. 63, Centro, CEP 97.015-003 - Santa Maria-RS, Brasil. E-mail: shana.wottrich@gmail.com
} 
allá de la enfermedad física, abarcando las más distintas áreas profesionales y de conocimiento en el ámbito de atención a la salud.

Palabras-clave: Psicología de la salud; cardiomiopatías; cirugía.

Em termos epidemiológicos, as doenças cardiovasculares, especialmente a doença arterial coronariana, constituem a maior causa de morte no Brasil e no mundo. No Brasil, no ano de 2010, a taxa de mortalidade específica (óbitos por 100.000 habitantes) por doença isquêmica do coração atingiu a marca de 52,4, correspondendo ao número absoluto de 99.955 óbitos (Brasil, 2011).

Diante de doenças cardíacas em geral, especificamente da doença arterial coronariana, o procedimento cirúrgico coloca-se como possibilidade de intervenção que vem resultando em benefícios em termos de qualidade de vida para o paciente (Takiuti et al., 2007). No ano de 2011 foram realizadas no Brasil cerca de 100.000 cirurgias cardíacas, das quais mais da metade era de revascularização miocárdica (Brail \& Godoy, 2012). Em estudo, que avaliou características epidemiológicas de pacientes submetidos a cirurgia cardíaca em um hospital especializado nesse procedimento, no Rio de Janeiro, entre 2004 e 2009, constatou que os pacientes tinham média de idade de 61,2 anos. Desses, 67,3\% eram do sexo masculino (Kaufman et al., 2011), o que reflete a realidade da doença, que afeta predominantemente homens. Considerando, então, a relevância da doença cardíaca no âmbito epidemiológico e a perspectiva do tratamento cirúrgico como produtor de bons resultados terapêuticos, esta pesquisa objetivou compreender os significados atribuídos à cirurgia cardíaca por pacientes précirúrgicos.

Este estudo considera a compreensão de que o coração não se constitui somente num órgão muscular oco, localizado no interior da cavidade torácica. Ele é considerado um órgão binário: representa a vida ou a morte, a sede das emoções e a fonte sentimentos. Nesse âmbito, é relevante apontar que um procedimento cirúrgico, ao propor uma intervenção no coração, também mobiliza fantasias e concepções individuais sobre o organismo físico $e$, ao mesmo tempo, sobre o indivíduo em sua subjetividade. Diante da experiência cirúrgica, tais fantasias determinarão a forma de enfrentar este procedimento (Romano, 2001).
Cumpre destacar que a cirurgia cardíaca não é um evento passível de controle pelo paciente (Ai, Peterson, Rodgers \& Tice, 2005; Ai, Peterson, Tice, Bolling \& Koening, 2004), sendo seu sucesso imediato determinado pela equipe cirúrgica ( $\mathrm{Ai}$ et al., 2005). No marco dessa caracterização, importa salientar que a espera pelo procedimento cirúrgico implica em um risco considerável de morte (Rexius, BrangrupWongnsen, Odén \& Jeppson, 2004). Tal espera influencia as reações emocionais à cirurgia (Bergvik, Sørlie \& Wynn, 2010), podendo acarretar intensa ansiedade ante a progressiva deterioração das condições de saúde, bem como problemas de adaptação no âmbito da vida afetiva, profissional e social (Haddad et al., 2002).

Nesse sentido, torna-se fundamental a preparação psicológica para esse processo, a qual inclui a busca por informações (Bergvik et al., 2010); porém essas informações devem ser oferecidas na medida de sua demanda por parte do paciente (Botega, 2006). Caso elas sejam detalhadas demais e não explicitamente solicitadas, podem gerar ansiedade desnecessária (Bergvik et al., 2010), pois desrespeitam as capacidades de elaboração psíquica do paciente. O processo de elaboração psíquica é conceituado como um processo de trabalho realizado pelo aparelho psíquico do indivíduo com o objetivo de dominar as excitações que se the apresentam, as quais correm o risco de acumular-se, tornando-se patogênicas (Laplanche \& Pontalis, 2001).

Entende-se, no marco do processo descrito, a necessidade de a equipe de saúde respeitar os mecanismos de defesa psíquicos utilizados pelos pacientes para o manejo das situações geradoras de ansiedade (Botega, 2006). Por mecanismos de defesa entende-se o conjunto de operações cujo objetivo é reduzir ou suprimir modificações da realidade que possam pôr em perigo a integridade e a constância do indivíduo, em termos biopsicológicos (Laplanche \& Pontalis, 2001). São recursos egoicos que o sujeito utiliza para "mascarar" a realidade que vivencia, pois tal realidade é causadora de sofrimento psíquico. Por exemplo, por meio do mecanismo de negação, o indivíduo pode passar 
a agir como se não estivesse sob ameaça, postergando o tratamento, deixando de acreditar em resultados de exames, ou, ainda, agindo evasivamente (Botega, 2006).

Quando o indivíduo utiliza tais mecanismos, principalmente em situações de vulnerabilidade como as que envolvem a doença e a cirurgia, considera-se que ele tem dificuldades para suportar a carga emocional advinda da experiência. Diante dessa realidade, não respeitar a capacidade de elaboração psíquica do paciente, forçando-o a ouvir informações sobre a doença e o tratamento, é uma atitude considerada violenta, porque acentua os níveis de ansiedade dele e dificulta que ele adote uma atitude colaborativa em relação ao tratamento. Destaca-se, assim, a necessidade de bom senso por parte dos profissionais, que devem adotar uma atitude de escuta atenta ao que o paciente deseja e suporta saber em diferentes momentos do processo de tratamento (Botega, 2006).

À luz da referida descrição de aspectos contextuais presentes na situação cirúrgica, cumpre apontar o entendimento de que a instituição hospitalar deve ser concebida como sistema aberto e como contexto gerador de significados (Moré, Crepaldi, Gonçalves \& Menezes, 2009). No tocante às práticas de atenção à saúde, ratifica-se o adequado manejo e oferta de informações para o paciente como um desafio importante para os profissionais que o atendem (Bergvik et al., 2010). Preconiza-se, assim, que a equipe de saúde tenha como prática uma escuta direcionada ao implícito, ao que não é falado, mas que está presente nas tramas de relações estabelecidas no espaço hospitalar (Moré et al., 2009).

Diante da iminência da cirurgia, é comum a presença do sentimento de medo (Bachion, Magalhães, Munari, Almeida \& Lima, 2004; Souza, Mantovani \& Labronici, 2006; Vargas, Maia \& Dantas, 2006). Tal sentimento pode mostrar-se vinculado à suposição de que 0 procedimento acarreta dor, à vulnerabilidade e ao sofrimento próprios da cirurgia em si e da hospitalização (Bachion et al., 2004) e à possibilidade de morte real (Bachion et al., 2004; Erdmann, Lanzoni, Callegaro, Baggio \& Koerich, 2013, Souza et al., 2006).

Além disso, a cirurgia representa a violação do corpo e traz o medo da agressão à integridade do sujeito (Souza et al., 2006). Quanto a esse sentimento, evidenciam-se relatos de desamparo e solidão, acentuados pela necessidade de o paciente separar-se dos referenciais familiares durante a internação hospitalar. Também existem relatos de sentimentos de apreensão (Bachion et al., 2004) e de insegurança com relação ao quadro de saúde no momento pós-cirúrgico (Erdmann et al., 2013), destacando-se expectativas relacionadas à cura da doença após a submissão ao procedimento (Hirani, Patterson \& Newman, 2008).

Paradoxalmente, a possibilidade de realizar o procedimento cirúrgico também representa sentimentos positivos e de esperança (Vargas et al., 2006). Nessa medida, a crença em um futuro melhor depois da cirurgia motiva os sujeitos a buscarem tal procedimento, que pode assumir uma dimensão de renascimento, de um recomeço de vida (Souza et al., 2006). Pela experiência da cirurgia, os pacientes que a ela se submetem podem significar a si mesmos como pessoas comuns, possivelmente voltando a desempenhar atividades do cotidiano e restaurando o senso de integridade sobre suas vidas. O que está em jogo, nesta perspectiva, é a possibilidade de ressignificar o uso do próprio corpo, pois a abertura do corpo físico coloca-se como um espaço potencial para a significação das possibilidades de vida após o procedimento (Radley, 2000).

Como a cirurgia é um tratamento invasivo e com carga significativa de dramaticidade quando comparada a outros tratamentos, parece ser o que traz mais certeza de cura e de controle da doença. Na perspectiva dos pacientes, a cirurgia é caracterizada como um tratamento definitivo, que resolverá o problema da doença, mas na realidade é uma alternativa a ser buscada apenas eventualmente, enquanto os demais tratamentos podem ser concebidos como transitórios no que diz respeito à cura (Hirani, Pugsley \& Newman, 2006; Hirani et al., 2008).

O futuro é outro aspecto que levam em conta pacientes pré-cirúrgicos cardíacos internados para a realização do procedimento (Bergvik et al., 2010). Os pacientes coronarianos são, com frequência, encorajados a alterar seus estilos de vida de forma a engendrar um senso de controle sobre sua condição de saúde física, independentemente dos efeitos do tratamento (Hirani et al., 2006). Assim, os questionamentos sobre o futuro imediato após o procedimento podem dizer respeito ao manuseio das medicações, à limpeza da ferida cirúrgica e à capacidade para desempenhar tarefas práticas 
em casa após a alta. Além disso, podem surgir algumas dúvidas sobre a habilidade para mudar o estilo de vida após a alta hospitalar, o que inclui rotinas e hábitos deletérios à saúde (Bergvik et al., 2010).

Outras preocupações sobre o futuro, além das que envolvem os cuidados imediatos após a cirurgia, dizem respeito à manutenção da qualidade de vida e ao retorno ao trabalho (Bachion et al., 2004; Souza et al., 2006). O trabalho, nesse âmbito, é compreendido como condição essencial para viver (Callegaro, Koerich, Lanzoni, Baggio \& Erdmann, 2012, Erdmann et al., 2013), tanto que os sentimentos de inutilidade e incapacidade provenientes da impossibilidade de ser produtivo são constrangedores para os sujeitos (Souza et al., 2006; Vila et al., 2008).

A religiosidade, enquanto estrutura de conhecimento mais amplo a respeito do mundo e de seu propósito, pode estar relacionada à forma de o paciente perceber e significar a doença crônica (Karademas, 2010). Este fator também está em jogo diante da decisão de submeter-se ou não à cirurgia, porquanto, paradoxalmente, esta representa tanto a possibilidade de viver quanto uma ameaça à vida (Ai et al., 2004). O descontrole subjacente à situação de cirurgia leva os sujeitos a buscar num ser supremo a confiança de que estão protegidos (Bachion et al., 2004; Souza et al., 2006, Vargas et al., 2006, Vila, Rossi \& Costa, 2008). Assim, a religião acaba assumindo um lugar de ordenação diante do caos promovido pela doença, diante dos medos e inseguranças e do risco de morte vivenciados. Por meio da religião os pacientes conferem sentido à situação de adoecimento e cirurgia, o que lhes permite integrar a doença a uma visão global da sua existência diante da impossibilidade de controlar a situação. Assim, a religião pode ser compreendida como uma forma de controle ilusório sobre o imponderável, representado pela situação cirúrgica (Vila et al., 2008).

No contexto descrito, a internação hospitalar para a realização do procedimento cirúrgico cardíaco é propícia para o desenvolvimento de um movimento reflexivo do sujeito, que pode passar a valorizar aquilo que faz parte de seu cotidiano fora do hospital (Bergvik et al., 2010), motivando mudanças saudáveis em sua vida. $A$ ação cirúrgica será considerada bem-sucedida apenas se for significada como "catastrófica" pelo indivíduo, ou seja, se mobilizar sentimentos e percepções que o instrumentalizem para se reorganizar (Romano, 2001). Assim, a doença pode ser significada pelo paciente como algo positivo, que torna possível um olhar mais consciente sobre sua vida e sobre os aspectos positivos de seu cotidiano (Bergvik et al., 2010).

\section{MÉTODO}

\section{Desenho do estudo}

O estudo proposto caracteriza-se como qualitativo, de caráter exploratório e descritivo. Entende-se que tal delineamento permite o aprofundamento dos significados que os sujeitos dão às suas ações e relações (Turato, 2008).

\section{Participantes}

A coleta de dados foi realizada em um serviço ambulatorial de atenção a pacientes précirúrgicos cardíacos de um hospital do Interior do Rio Grande do Sul. O referido ambulatório assume a atribuição de avaliar as condições clínicas dos pacientes pré-cirúrgicos cardíacos mediante consultas a um cardiologista clínico, alocando-os em lista de espera para o procedimento, sendo a ordem da realização das cirurgias definida de acordo com critérios clínicos médicos preestabelecidos. $\mathrm{O}$ ambulatório de pacientes pré-cirúrgicos cardíacos iniciou seu funcionamento no período da coleta de dados de novembro de 2009 a janeiro de 2011. Nessa ocasião três pacientes pré-cirúrgicos eram atendidos pelo serviço semanalmente.

Participaram deste estudo quinze pacientes pré-cirúrgicos cardíacos (nove homens e seis mulheres), com idades que variaram de 47 a 73 anos, sendo que no momento da realização da entrevista nenhum estava desempenhando atividade profissional. Desses indivíduos, onze estavam aguardando cirurgia de revascularização miocárdica e quatro aguardavam cirurgia para a colocação de prótese valvar cardíaca. Optou-se por recrutar pacientes pré-cirúrgicos cardíacos, com ambas as patologias cardíacas, porque o objetivo do estudo era identificar os significados atribuídos pelos pacientes à cirurgia cardíaca, que era realizada mediante indicação para o procedimento, independentemente do tipo de doença cardíaca. Cumpre ainda destacar que, para assegurar a homogeneidade das características dos participantes da pesquisa, considerou-se que as duas patologias implicam 
em procedimentos cirúrgicos e repercussões pós-operatórias comuns a ambas, como, por exemplo, a utilização da anestesia geral, a realização da esternotomia (incisão no músculo esterno para que o cirurgião tenha acesso ao coração), a utilização de circulação extracorpórea, a permanência em unidade de tratamento intensivo após o procedimento, o período de readaptação a uma nova rotina de vida, entre outros.

Para serem incluídos na pesquisa os pacientes deveriam ter cirurgia prevista para data não superior a seis meses desde a realização do primeiro contato com a pesquisadora. A opção por realizar entrevistas com pacientes pré-cirúrgicos nessas condições é justificada pelo entendimento de que essa extensão de tempo permitiria aos participantes refletirem sobe a experiência cirúrgica futura. Foram excluídos do estudo pacientes menores de dezoito anos, os que não residissem na cidade onde se realizou o estudo e que, em função de disfunções físicas, não pudessem falar. O número de entrevistados foi determinado pelo critério de saturação da amostra, segundo o qual, quando os dados coletados deixam de ser novos e configuram estrutura comum sobre o tema estudado, finaliza-se a coleta de dados (Fontanela, Ricas \& Turato, 2008).

\section{Técnicas e procedimentos de coleta de dados}

A coleta de dados consistiu na realização de entrevistas individuais semiestruturadas, mediante contato pessoal (mediado pela equipe médica) com os pacientes usuários do referido ambulatório. Tais entrevistas se deram em local e horário escolhidos pelos participantes, de modo que algumas aconteceram no próprio ambiente hospitalar e outras nas residências dos entrevistados. As entrevistas não foram baseadas em perguntas, mas conduzidas a partir de eixos norteadores (o diagnóstico da doença, a indicação cirúrgica, o paciente antes da cirurgia, expectativas diante da cirurgia), a respeito dos quais os participantes eram convidados a falar. O entrevistador atuava no sentido de apontar questões para aprofundar o conteúdo das narrativas sobre os eixos em questão, de forma a responder aos objetivos do estudo. Todas as entrevistas foram gravadas, com o consentimento dos participantes, e posteriormente transcritas na íntegra, para fins de análise.

\section{Procedimentos de análise dos dados}

Todas as entrevistas foram analisadas conforme a análise de conteúdo proposta por Bardin (1977/2008) e Turato (2008), segundo a qual os elementos são categorizados pelos critérios de relevância e repetição (Turato, 2008). Utilizou-se uma perspectiva de refinamento da análise de conteúdo, conforme propõe Turato (2008). Segundo esta proposta, ao longo da análise deve-se atentar para o conteúdo latente das narrativas, o "querer dizer" dos fenômenos para os sujeitos. Trata-se de uma proposta de escuta do implícito, alicerçada nos preceitos da psicanálise. Assim, tal técnica de análise de conteúdo das narrativas prevê que o pesquisador atente para o que não é dito, mas pode ser inferido pelo pesquisador mediante a análise do contexto da entrevista, na qual se consideram tanto as narrativas quanto as reações emocionais dos participantes. Segundo essa proposta de análise, os referidos elementos devem ser cuidadosamente considerados na categorização.

\section{Considerações e aspectos éticos}

Foram seguidas as recomendações éticas da Resolução 196/96 do Conselho Nacional de Saúde, que normatiza as condições para a realização de pesquisas que envolvam seres humanos. As atividades de campo previstas para esta pesquisa só foram desenvolvidas após a aprovação do comitê de ética da instituição em que foi realizada, sendo o projeto aprovado sob número CAAE 0174.0.243.000-09. Com o objetivo de preservar 0 anonimato dos participantes, as falas ilustrativas das categorias serão seguidas das letras $M$ ou $F$ (Masculino ou Feminino) e da idade do participante.

\section{RESULTADOS E DISCUSSÃO}

Entre os resultados alcançados mediante a análise dos dados destacaram-se as categorias, por pontuarem questões de relevância quanto a vivências e expectativas quanto à indicação cirúrgica.

\section{A ansiedade da espera}

Esta categoria emergiu da experiência vivenciada pelos participantes, de ser indicada a eles a realização de cirurgia, ainda que fosse desconhecida a data em que tal procedimento 
iria acontecer. Nesse sentido, as falas trazem a ideia de que a doença é uma situação limítrofe e que a demora em realizá-la poderia resultar em complicações maiores ou até na morte (Rexius et al., 2004). Isto significa que esse cenário pode influenciar as reações emocionais à cirurgia (Bergvik et al., 2010), conforme referem as narrativas. "Então, estou aguardando um tanto nervoso, porque não chega o dia de fazer essa cirurgia. Já tive aqui duas vezes e não consegui a baixa, e isso deixa a gente meio..." (M4, 68 anos).

E era pra ser urgente isso aí. Era uma urgência, mas já fez um ano, porque ele [o médico] viu eu tão ruim que já pediu urgência. Todas as fichas ele já botava ali com urgência. E até agora, que urgência nada... (M1, 48 anos).

A fala acima traz a ambivalência destacada por muitos pacientes, no sentido de ficarem em dúvida acerca da severidade da situação. A ideia de que a patologia cardíaca, por si, já é uma situação emergencial (Romano, 2001) e a vivência da espera pelo chamamento para a realização do procedimento podem atuar como acentuadores do mecanismo de defesa, de negação (Botega, 2006). Além disso, a ausência de sintomas é um fator que pode contribuir para a negação da doença (Hirani et al., 2006) e, por conseguinte, do procedimento.

A incerteza acerca da data da realização do procedimento e os consequentes sentimentos também se evidenciaram nos acontecimentos que atravessaram a realização das entrevistas. Cabe destacar que chegou ao conhecimento da pesquisadora que um dos participantes, M4, foi chamado para a realização do procedimento repentinamente, devido à piora do seu quadro clínico. Esse acontecimento ilustra a condição de impossibilidade de controle da cirurgia por parte dos pacientes, pela imprevisibilidade da condição clínica deles. Tal situação evidencia também a sensação de prontidão e alerta vivenciada por alguns pacientes, pois em algumas falas parece existir uma sobrecarga emocional. A referida sobrecarga é evidenciada na descrição dessa categoria, uma vez que o relato das experiências dos pacientes à pesquisadora foi marcado por intensas reações emocionais, como choro, voz trêmula, narrativa truncada. A narrativa de M4, ilustrada acima, por exemplo, foi marcada pela dificuldade do entrevistado em dar continuidade ao seu relato, como se pode verificar no final da fala ilustrativa supramencionada, que é finalizada pelo paciente sem que ele consiga nomear os seus sentimentos.

Esses resultados coincidem com os de uma pesquisa realizada por Bergvik et al. (2010). Os pacientes pré-cirúrgicos cardíacos entrevistados no referido estudo relataram estarem aborrecidos, entristecidos, sentindo-se vulneráveis e amedrontados, agarrando-se à esperança de que a cirurgia "miraculosamente" não fosse mais necessária. Além desses efeitos "negativos", é relevante salientar que a ansiedade pode ser potencializadora de mudanças na vida dos sujeitos, ao possibilitar reflexões sobre a vida e preparação para o procedimento. Nesse cenário, as cirurgias eletivas permitem uma preparação no tocante tanto ao aspecto somático quanto ao psicológico (Bergvik et al., 2010).

Cabe ressaltar que ao longo do processo de coleta de dados houve uma reestruturação significativa na organização do tempo de espera para a realização da cirurgia. Tal alteração resultou no encurtamento do período de espera dos pacientes pré-cirúrgicos para, no máximo, trinta dias entre o momento de avaliação da equipe médica, a entrada na lista de espera e a realização do procedimento cirúrgico. Essa redução deveu-se ao processo de organização das atividades do ambulatório, conforme está previsto no método. Com base nessa alteração na logística de realização das cirurgias, pode-se supor que o cenário de ansiedade intensa diante do desconhecido tenha sido amenizado.

\section{A cirurgia e o medo}

Diante do conhecimento da necessidade de realizar o procedimento, o sentimento de medo (Bachion et al., 2004; Souza et al., 2006; Vargas et al., 2006) emergiu nos depoimentos dos participantes de forma explícita ou latente. $\mathrm{Na}$ narrativa a seguir, evidencia-se um exemplo em que o sentimento de medo mostra-se de forma explícita.

[Riso breve]. Eu achei, eu disse pra ela que era pra nós esperar mais um pouco, né? [risos] que eu tinha medo de... Eu até falei com o doutor também que eu tinha medo de fazer, né, e então ele disse: "Então vamos esperar." (F1, 73 anos) 
A análise da narrativa de $\mathrm{F} 1$ permite inferir que o medo se mostra explícito quando é referido claramente, mesmo que com dificuldades. A dificuldade de verbalizar o medo pode ser percebida pela descontinuidade da narrativa e pela pausa, expressa na transcrição pelas reticências, justamente quando a participante aborda a questão do medo. A próxima narrativa ilustra o medo expresso de forma latente.

Ah, eu não penso, se der certo tudo bem. (risos) Essa hora já não tem muita... seja lá como Deus quiser, como diz o outro. Eu encaro numa boa. Procuro não pensar que é pra não... deixo, deixo ir passando. (F6, 56 anos)

$\mathrm{Na}$ fala de F6 destaca-se a dificuldade da participante em refletir acerca do acontecimento, apenas tangenciando $o$ relato de seus sentimentos. Tal dificuldade evidencia-se pela análise da contradição presente na narrativa pelo conteúdo implícito nela. Embora F6 afirme que "encara numa boa", ela refere que procura "não pensar" na cirurgia. Essa contradição pode ser compreendida como uma forma de evitar o temor que o procedimento cirúrgico provoca. As pausas entre as palavras (expressas pelas reticências) indicam a presença de um temor que não é explicitado em palavras, mas na entonação de voz e na dificuldade de finalizar as frases. A presença da ansiedade nas narrativas de ambas as entrevistadas (F1 e F6) também pode ser depreendida por meio do riso, reação contraditória delas ao abordarem um assunto de tanta seriedade como a cirurgia. Assim, essas falas ilustram a dificuldade dos pacientes em colocar-se numa situação de passividade diante da cirurgia, perdendo o controle de suas vidas (Ai et al., 2004, 2005) e entregando-as para a equipe.

Também se evidenciou nas falas o caráter limítrofe da situação de indicação cirúrgica, uma vez que a cirurgia representa riscos para a vida (Ai et al., 2004), mas ficar sem ela pode culminar em morte. Esse caráter limítrofe engendra-se num panorama de sobrecarga afetiva, sendo as vivências permeadas por dúvidas e incertezas diante da antecipação do desconhecido, representado pela cirurgia.

[Em prantos] É, deixa eu sofrer, deixa eu chorar, deixa eu sentir. Eu tenho certeza que tem que fazer, eu tô contente que eu vou fazer a operação, porque se eu não fizer eu sei que eu vou morrer. Então eu tenho direito de sofrer, de chorar, de botar pra fora, né, e os meus filhos acham que eu sou muito medrosa... ... Não vai ter risco, né. No ganhar [filho, na situação de parto] tu faz uma cesariana, mas no coração é bem diferente, né. Então, eu tenho sofrido muito (F2, 67 anos).

Na narrativa de F2 constata-se a sobrecarga afetiva pela reação emocional observada na fala. A paciente chorou intensamente ao abordar a temática, não conseguindo assumir declaradamente o medo que sentia e, de certa forma, negando-o, ao dizer que a cirurgia não envolveria riscos; mas na frase anterior, F2 assume indiretamente a presença do medo ao atribuir a afirmação aos filhos ("Os filhos acham que eu sou muito medrosa"). A narrativa de M3, a seguir, também traz uma perspectiva em que o medo fica latente, subjacente ao explicitado.

\section{... mas, é fazer, e outra coisa que eu não queria fazer, eu não queria fazer, não queria abrir, tu entendeu?. Sinceramente, eu não gostaria de mexer.... Ele [o médico] sempre me disse assim: "Meu filho, depois de porta arrombada não adianta tranca de ferro." (M3, 47 anos)}

O medo se faz presente, mesmo que de forma implícita, no desejo expresso de não realizar a cirurgia; desejo que é justificado e sustentado em uma metáfora utilizada pelo discurso médico. De forma enfática, a última fala ilustra o sentimento de vulnerabilidade que emerge diante da realização do procedimento. Nesse contexto, parece haver a expectativa de uma ruptura da integridade do corpo, que não será mais o mesmo depois da cirurgia (Souza et al., 2006).

\section{Expectativa de futuro após a cirurgia}

Após a cirurgia, a expectativa dos participantes parece ser a de resgatar os hábitos anteriores à doença, de forma a terem um senso de continuidade em suas histórias de vida. Essa realidade pressuposta, por um lado, parece ser a que mobiliza os pacientes a submeterem-se ao procedimento. Neste sentido, a cirurgia parece ser significada como benéfica, pois se pressupõe a possibilidade de melhores condições de saúde; no entanto tais ganhos devem ser relativizados, devendo 0 paciente entender que 0 
procedimento cirúrgico é apenas outro tipo de tratamento para uma patologia crônica que continuará a existir (Vargas et al., 2006). Isso nem sempre acontece, pois alguns trazem em suas falas a expectativa de retomar seu ritmo de vida, considerando a cirurgia como um tratamento resolutivo e definitivo (Hirani et al., 2006, 2008).

Não sei, acho que vai ser, vai ser, vai ser melhor, porque eu acho... como é que eu vou te dizer... eu acho que é, vai ser, que agora eu não posso fazer nada, mas depois que eu sarar bem posso levar uma vida normal igual a antes, eu acho. (M2, 66 anos)

Que eu espero que eu faça a cirurgia e vou melhorar ... Ali eles mostraram, ali o coração a veia. O coração dá uma paradinha porque a veia tá meia entupida. Quando ele dá aquela paradinha, é porque ele fecha a veia. E isso aqui tem que cortar bem, limpar que é pra... aí vai trabalhar normal. (M6, 73 anos)

A palavra "normal" referida nas duas narrativas ilustrativas pode ser compreendida como alusão a expectativas de retomada das condições de vida anteriores ao adoecimento. $\mathrm{Na}$ fala de M2, o paciente aborda a expectativa de resgate das condições ocupacionais, enquanto na fala de M6 a normalidade refere-se ao resgate das condições orgânicas e fisiológicas do coração.

A cirurgia também aparece nos relatos como uma possibilidade de potencializar a qualidade de vida. Nesse caso, os relatos centram-se nas limitações provenientes da doença e trazem a esperança de que tais limitações serão superadas através do procedimento."Pra senhora entender mais melhor, assim, é que eu estou fraco demais. Então quem sabe essa cirurgia vai me trazer uma nova vida, uma nova esperança." (M9, 57 anos) "Ah, eu espero viver uns bons anos ainda. Esse é a minha preocupação em viver mais alguns anos, 0 máximo. E me cuidar, é claro que eu vou ter que me cuidar." (M4, 68 anos)

Também é relevante salientar que alguns pacientes não atribuem apenas ao procedimento a possibilidade de resgatar/manter/construir uma melhor qualidade de vida, considerando a cirurgia como um marco da possibilidade de renascimento (Souza et al., 2006). Neste sentido, apropriam-se do processo de tratamento, responsabilizando-se pelos frutos que colherão dele; ou seja, como refere a última fala, a cirurgia traz benefícios em termos de sobrevida, mas para que isso ocorra, é necessário que o paciente tenha cuidado.

\section{Religiosidade e introspecção}

Consoante aos dados trazidos pela literatura, a cirurgia pode significar, para alguns, uma oportunidade de reflexão e resgate do passado, da relação com os demais e das crenças religiosas. Neste sentido, alguns relatos trazem a religiosidade como fonte de suporte diante da iminência da cirurgia. Diante da impossibilidade de controle, alguns indivíduos buscam em um ser superior o conforto e a segurança (Bachion et al., 2004; Souza et al., 2006, Vargas et al., 2006; Vila et al., 2008).

\begin{abstract}
Aí, nesse meio que a gente, eu tava perdido e coisa, né, a minha esposa, assim: vamos fazer uma cirurgia espiritual. Digo: Vamos. ... No momento que eu fiz essa cirurgia eu, não sei se a senhora acredita ou não, eu fiquei recebendo um mentor espiritual ... Aí eu comecei a ver o mundo diferente, eu comecei a ver as coisas diferentes, que não era só aquele mundo que eu pensava. (M3, 47 anos)
\end{abstract}

$\mathrm{Na}$ narrativa de M3 evidencia-se o poder da religião como meio de conferir sentido à situação de adoecimento e cirurgia, possibilitando que as repercussões do procedimento sejam integradas a uma visão global da existência dos sujeitos (Vila et al., 2008). A fala seguinte é ilustrativa do aspecto reflexivo potencializado pela iminência da experiência cirúrgica. A partir dos sentimentos despertados pela situação, pode haver um movimento de ressignificação de si mesmo, de escolhas e de uso do próprio corpo (Radley, 2000).

Mas, mesmo assim, eu acho que é hora
de ficar em casa. Ficar em casa pra
olhar pros netos, brincar com os netos, e
é isso aí. Estou até esperançoso que
isso aí chegue e que eu consiga voltar a
ter uma boa saúde, que é pra desfrutar
com eles assim. ... Porque ... eu ficava
muito tempo longe de casa. ... Então eu
ficava, dependendo do lugar, eu ficava
até três semanas sem ir em casa. A
minha filha, quando nasceu, foi uma
dificuldade assim pra... pra ela; nem me 
chamava de pai. ... Ela foi crescendo e não me via quase em casa. E então, ficou tudo bem, mas no comecinho assim, ela não, não sabia quem era. "Quem é esse aí?" "Esse é o pai que tá aí." ... Então, agora é hora de recuperar um pouco. (M4, 68 anos).

Dessa forma, a cirurgia também pode ser concebida em seus aspectos potencializadores, servindo como um meio de os sujeitos reorganizarem suas vidas e suas relações (Romano, 2001; Bergvik et al., 2010). A consciência de maior cuidado consigo e com as relações parece ficar registrada na fala acima, destacando as construções que acontecem ao longo da vida em seus aspectos processuais.

\section{CONSIDERAÇÕES FINAIS}

Este artigo traz um recorte de significados da cirurgia cardíaca para pacientes pré-cirúrgicos, enfatizando os aspectos concebidos como limitadores e potencializadores do procedimento. Os depoimentos evidenciam a ansiedade diante do desconhecido e da falta de controle representada pela cirurgia e se referem ao medo diante do procedimento, que ora parece remeter à vida, ora à morte. As expectativas para a vida após o procedimento cirúrgico remetem à perspectiva de uma vida em que não há problemas cardíacos e à necessidade de os pacientes se responsabilizarem por seus próprios quadros de saúde. Nessa direção, é atribuída à situação cirúrgica, em alguns casos, a motivação para a apropriação dos sujeitos sobre seus corpos e suas vidas.

Cumpre salientar que o presente estudo recrutou pacientes usuários de um serviço ambulatorial pré-cirúrgico em início de organização institucional, o que pode ter influenciado o caráter de imprevisibilidade da situação de espera pelo procedimento, para os pacientes. Embora se reconheça esta situação singular, os possíveis atravessamentos desse cenário não foram explorados e discutidos neste estudo com a necessária profundidade.

No marco dessa especificidade, este estudo aborda os significados emergentes para os pacientes pré-cirúrgicos, em decorrência da vivência de um período de previsão de realização da cirurgia de no máximo seis meses. Tratava-se apenas de uma previsão de tempo de espera, que era comunicada pelo médico ao paciente, visto que a ordem exata de pacientes na lista de espera para a cirurgia estava limitada à disponibilidade de leitos no hospital, às condições clínicas dos pacientes e às situações emergenciais. Assim, não havia uma delimitação específica quanto à data para a realização da cirurgia no momento anterior à realização da entrevista. Outras pesquisas poderão complementar as discussões travadas neste trabalho e aprofundá-las, delimitando a abordagem de pacientes pré-cirúrgicos para a pesquisa, tendo como margem um período mais específico de espera pelo procedimento.

Postas essas limitações, evidencia-se que a presente pesquisa contribui com os estudos existentes sobre a situação de espera para a realização da cirurgia cardíaca, no sentido de salientar as repercussões emocionais implicadas no caráter de imprevisibilidade atribuído ao momento. As narrativas destacam a situação de vulnerabilidade e de fragilidade emocional que decorre não apenas da cirurgia, mas também da espera pelo procedimento. Entende-se que a sobrecarga emocional esteve presente, de forma transversal, em todas as categorias, e que a compreensão e a discussão desse aspecto foi apenas possível mediante uma modalidade de análise que atentou para o conteúdo implícito nas narrativas. Assim, entendemos que 0 presente estudo também trouxe contribuições metodológicas para o cenário da pesquisa em saúde, ao propor uma perspectiva de análise de conteúdo específica nesse contexto.

Independentemente dos matizes individuais dos relatos que compõem este estudo, uma característica parece perpassá-los: evidencia-se a vivência de um montante significativo de sofrimento. Em decorrência dessa constatação, torna-se necessário resgatar a importância da reflexão sobre aspectos da cirurgia que estão além do adoecimento físico. Tais questões devem ser enfatizadas e mais amplamente trabalhadas de forma interdisciplinar, abarcando as mais diversas áreas profissionais e de conhecimento que se propõem a acolher e cuidar dos usuários do sistema de saúde brasileiro que aguardam a realização da cirurgia cardíaca.

\section{REFERÊNCIAS}

Ai, A. L.; Peterson, C.; Rodgers, W. L., \& Tice, T. N. (2005). Faith factors and internal health locus of 
control in patients prior to open-heart surgery. Journal of Health Psychology, 10, 669-676.

Ai, A. L., Peterson, C., Tice, T. N., Bolling, S.F, \& Koening, H. G. (2004). Faith-based and secular pathways to hope and optimistic subconstructs in middle-aged and older cardiac patients. Journal of Health Psychology, 9,435-450.

Bachion, M. L., Magalhães, F. G. S., Munari, D. B., Almeida, S. P., Lima, M. L. (2004). Identificação do "medo" no período pré-operatório de cirurgia cardíaca. Acta Paulista de Enfermagem, 17, 298304.

Bardin, L. (2008). Análise de Conteúdo. (L.A. Reto, \& A. Pinheiro, Trad.). Lisboa: Ed. 70. (Original publicado em 1977).

Bergvik, S., Sørlie, T., \& Wynn, R. (2010). Approach and avoidance coping and regulatory focus in patients having coronary artery bypass surgery. Journal of Health Psychology, 15, 915-924.

Botega, N.J. (2006). Reação à doença e à hospitalização. In N. J. Botega (Org.), Prática psiquiátrica no hospital geral: interconsulta e emergência (pp. 49-66). Porto Alegre: Artmed.

Brail, D.M., \& Godoy, M. F. (2012). History of heart surgery in the world. Revista Brasileira de Cirurgia Cardiovascular, 27(1), 125-34.

Brasil. Ministério da Saúde. (2011). Indicadores e dados básicos. Recuperado em 15 abril, de 2013, de http://tabnet.datasus.gov.br/cgi/deftohtm.exe?idb 2011/c08.def.

Callegaro, G. D., Koerich, C., Lanzoni, G. M. M., Baggio, M. A., \& Erdmann, A. L. (2012). Significando o processo de viver a cirurgia de revascularização miocárdica: mudanças no estilo de vida. Revista Gaúcha de Enfermagem, 33(4), 139-149.

Erdmann, A. L., Lanzoni, G. M. M., Callegaro, G. D., Baggio, M. A., \& Koerich, C. (2013). Compreendendo o processo de viver significado por pacientes submetidos a cirurgia de revascularização do miocárdio. Revista LatinoAmericana de Enfermagem, 21(1), 8 telas. Recuperado em 3 Outubro, de 2013, de http://www.scielo.br/pdf/rlae/v21n1/pt_v21n1a07. pdf.

Fontanela, B. J. B., Ricas, J., \& Turato, E. R. (2008). Amostragem por saturação em pesquisas qualitativas em saúde: contribuições teóricas. Cadernos de Saúde Pública, 24, 17 - 27.

Haddad, N., Bittar, O. J.N.V., Pereira, A. A. M., Silva, M. B. da, Amato, V. L., Farsky, P. S., Ramos, A. I. O., Sampaio, M., Almeida, T. L. V., Armaganijan, D., \& Sousa, J. E. M. R. (2002). Consequências do prolongamento do tempo de espera em pacientes candidatos à cirurgia cardíaca. Arquivos Brasileiros de Cardiologia, 78, 452-458.

Hirani, S. P., Patterson, D, L. H., \& Newman, S. P. (2008). What do coronary artery disease patients think about their treatments? An assessment of patients' treatment representations. Journal of Health Psychology, 13, 311-322.

Hirani, S.P., Pugsley, W.B., \& Newman, S.P. (2006). Illness representations of coronary artery disease: an empirical examination of the Illness Perception Questionnaire (IPQ) in patients undergoing surgery, angioplasty and medication. British Journal of Health Psychology, 11, 199220.

Karademas, E. C. (2010). Illness cognitions as a pathway between religiousness and subjective health in chronic cardiac patients. Journal of Health Psychology, 15, 239-247.

Kaufman, R., Kuschnir, M. C. C., Xavier, R. M. A., Santos, M. A., Chaves, R. B. M., Müller, R. E., Pinheiro, M. C. C. M., Ribeiro, A. L. P., \& Azevedo, V. M. P. (2011). Perfil epidemiológico da cirurgia de revascularização do miocárdio. Revista Brasileira de Cardiologia, 24(6), 369-376.

Laplanche, J. \& Pontalis, J. B. (2001). Vocabulário de psicanálise. (P. Tamem, Trad.). São Paulo: Martins Fontes.

Moré, C. L. O. O., Crepaldi, M. A., Gonçalves, J.A, \& Menezes, M. (2009). Contribuições do pensamento sistêmico à prática do psicólogo hospitalar. Psicologia em Estudo, 14, 465-473.

Radley, A. (2000). Health psychology, embodiment and the question of vulnerability. Journal of Health Psychology, 5, 297-304.

Rexius, H., Brangrup-Wongnsen, G., Odén, A., \& Jeppson, A. (2004). Mortality in the waiting list for coronary artery bypass grafting: incidence and risk factors. Annals of Thoracic Surgery, 77, 769775.

Romano, B. W. (2001). Aspectos psicológicos e sua importância na cirurgia das coronárias. In B. W. Romano (Org.), Psicologia e cardiologia: encontros possíveis (pp. 111-144). São Paulo: Casa do Psicólogo.

Souza, R. H. S., Mantovani, M. F., \& Labronici, L. M. (2006). O vivido pelo cliente em pré-operatório de cirurgia cardíaca. Online Brazilian Journal of Nursing, 5. Recuperado em 1 Abril, de 2012, de http://www.objnursing.uff.br/index.php/nursing/arti cle/view/403/97.

Takiuti, M. E., Hueb, W., Hiscock, S. B., Nogueira, C. R. S. da R., Girardi, P., Fernandes, F., Favarato, D., Lopes, N., Borges, J. C., Góis, A, F. T. de, \& Ramires, J. A. F. (2007). Qualidade de vida após revascularização cirúrgica do miocárdio, angioplastia ou tratamento clínico. Arquivos Brasileiros de Cardiologia, 88, 537-544.

Turato, E. R. (2008). Tratado da metodologia da pesquisa clínico-qualitativa. Petrópolis: Vozes.

Vargas, T. V. P., Maia, E. M., \& Dantas, A. S. D. (2006). Sentimentos de pacientes no pré-operatório de cirurgia cardíaca. Revista Latino-americana de Enfermagem, 14. Recuperado em 1 Abril, de 2012, de http://www.scielo.br/pdf/rlae/v14n3/pt_v14n3a12.pdf. 
Vila, V. S. C., Rossi, L. A., \& Costa, M. C. S. (2008). Experiência da doença cardíaca entre adultos submetidos à revascularização do miocárdio. Revista de Saúde Pública, 42, 750-756.

Shana Hastenpflug Wottrich: psicóloga, mestre em Psicologia pelo Programa de Pós-Graduação em Psicologia da Universidade Federal de Santa Maria, doutoranda pelo Programa de Pós-Graduação em Psicologia da Universidade Federal de Santa Catarina.

Alberto Manuel Quintana: psicólogo, pós-doutorado pela Universidade Complutense de Madrid, Espanha, doutor em Ciências Sociais, professor do Curso de Graduação e do Programa de Pós-Graduação em Psicologia da Universidade Federal de Santa Maria.

Valéri Pereira Camargo: psicóloga, mestre em Psicologia pelo Programa de Pós-graduação em Psicologia da Universidade Federal de Santa Maria.

Carlos Oclides Pereira de Quadros: acadêmico do curso de graduação em Psicologia da Universidade Federal de Santa Maria.

Alexandre Antonio Naujorks: médico, mestre em Ciências Médicas - Pediatria, pela Universidade Federal do Rio Grande do Sul, doutorando em Ciências Médicas - Cardiologia, pela Fundação Universitária de Cardiologia-RS. 